\title{
PENYELESAIAN PROBLEM HUKUM MELALUI PENDEKATAN MAQASID SHARI'AH
}

\author{
Edi Susilo \\ Institut Agama Islam Negeri Metro, Lampung \\ Email: edi_susilo13@yahoo.com
}

\begin{abstract}
Abstrak
The Maqasid Shari'ah theory finds its urgency when it is formulated as an alternative to solve various matters related to the formulation of law. Interestingly Maqasid Shari'ah can be transformed in the present context, in the field of law, social and even economic issues, and others. Because indeed the Maqasid Shari'ah theory is formulated to deal with changes, the induction method which is the basis of the theory is the keyword that causes it to be dynamic and can be applied in different contexts. This research is library research. It will explore Maqasid Sharia as a method in istinbath Law. The results of the study are, that Maqasid Shar'iah can be used as an approach in ijtihad to respond to the development of the times by still referring to the al-Qur'an and al-Hadith, by combining particular texts and global intentions. Whereas to find out the Maqasid Shari'ah can be done through istiqra '(taking several samples) for the shari'at applied, and by studying the arguments of the verses of the al-Quran.
\end{abstract}

Keywords: Maqasid, Syari'ah, Istinbath, Law.

\section{A. Pendahuluan}

Tidak ada satupun hukum yang telah ditetapkan oleh Allah swt. untuk hambaNya, kecuali untuk kebaikan dan kemaslahatan. Oleh karena itu, semua pembebanan syari'at kepada manusia adalah untuk memelihara sebuah kemaslahatan. Tujuan syari'at yang telah diformulasikan oleh Allah tersebut tidaklah keluar dari tiga bagian, yakni: Pertma, Daruriyyat, Kedua, Hajiyyat dan Ketiga Tahsiniyyat. ${ }^{1}$

Abu Ishaq al-Shatiby, dalam kitabnya yang sangat terkenal, berjudul: AlMuwafaqat fi Usul al-Shari'ah begitu pula Al-Ghazali dan gurunya Al-Juwaini, sudah mulai melihat hukum Islam dari aspek tujuan syari'at.

Memahami tujuan syari'at adalah inti dari semua penelitian dan pengkajian dalam ilmu usul fiqh. ${ }^{2}$ Sedangkan Al-Quran dan Sunnah menjadi landasan untuk mengkaji hukum shar'i. Sebagaimana telah dipahami bahwa hukum terus berkembang sesuai dengan perkembangan zaman, maka ephistemologi pembahasan tentang hal tersebut harus terus berkembang pula. Seperti dalam fiqh klasik yang membahas tentang kewajiban mengeluarkan zakat tumbuhtumbuhan, hanya dibatasi pada tumbuhan yang menadi makanan pokok, seperti wajibnya zakat gandum, padi, jagung dan makanan pokok lainnya. Sedangkan kelapa, sawit, serta biji-bijian lainnya termasuk rempah-rempah walaupun mahal harganya tidak digolongkan dalam tumbuhan yang wajib dizakati. Begitu halnya dengan zakat profesi, gaji dan pengasilan yang sah lainnya selain perniagaan, juga tidak wajib dizakat, dengan alasan tidak ada'illat hukum dan tidak ada dalil teks dari Al-Quran dan Sunnah Rasulullah SAW.

${ }^{1}$ Wahbah az-Zuhaily, al-Wajiz fi Usul al-Figh, (Beirut: Dar al-Fikr, 2010) hal 219-222. Lihat juga Abu Ishaq Al-Shatiby, Al-Muwafaqat fi Usul al-Shari'ah, (Libanon: Dar al-Ma'rifah,1997), h. 324. 2Firdaus, Ushul Fiqh,(Jakarta: Zikrul Hakim, 2004), h. 236. 
Namun, setelah para ulama Islam terus mengkaji hukum shar'i ini pada aspek al-Maqasid al-Shari'ah, menemukan perkembangan 'llah hukum makanan pokok menjadi 'illah "produktif". Sehingga, sederet benda yang dulunya belum masuk dalam daftar benda wajib zakat, maka kemudian menjadi wajib dizakati karena illahnya produktif.

Maka menarik untuk mengkaji lebih dalam tentang Maqasid Syariah sebagai metode dalam menemukan sebuah hukum seiring problematika kehidupan saat ini semakin kompleks, begitu pula hukum akan terus berkembang dan berubah seiring dengan perubahan peradaban manusia.

\section{B. Metode Penelitian}

Metode penelitian yang digunakan dalam kajian ini adalah penelitian kepustakaan (library research) dengan pendekatan kualitatif. Karena pendekatan yang dipakai kualitatif, maka aspek yang menonjol adalah upaya memecahkan makna berdasarkan objek kajiannya. Atas dasar ini, data yang diburu dalam penelitian ini adalah penjelasan tentang Maqasid Syariah sebagai metode dalam istinbath Hukum seiring dengan berkembangnya problematika kehidupan saat ini, berikut mengkaji kehujan dari Maqasid Syariah. Sumber data yang digunakan adalah bahan-bahan kepustakaan. Rujukan utama berupa Al-Qur'an dan AlHadis kemudian didukung oleh rujukan-rujukan berupa kitab-kitab yang membahas seputar Maqasid Syariah.

\section{Pembahasan}

\section{C.1. Ephistimologi Maqasid Shari'ah}

Makna Syari'at adalah hukum yang ditetapkan oleh Allah bagi hambaNya tentang urusan agama, baik berupa ibadah atau mu'amalah, yang dapat menggerakkan kehidupan manusia. ${ }^{3}$ Maksud-maksud syari'at adalah tujuan yang menjadi target teks dan hukum-hukum partikular untuk direalisasikan dalam dalam kehidupan manusia, baik berupa perintah, larangan dan mubah, untuk individu, keluarga, jamaah dan umat. ${ }^{4}$ Maksud-maksud juga bisa disebut dengan hikmah-hikmah yang menjadi tujuan ditetapkannya hukum. Karena setiap hukum yang disyari'atkan Allah untuk hambaNya, pasti terdapat hikmah, yang bisa diketahui oleh orang yang mengetahuinya, karena tidak mungkin Allah membuat syari'at dengan sewenang-wenang, sia-sia, atau kontradiksi dengan sebuah hikmah. 5

Maksud-maksud syari'at ini bukanlah illat yang disebutkan oleh para ahli ushul fiqh dalam bab qiyas, dan didefinisikan dengan sifat yang jelas, tetapi seasuai dengan hukum. Al-Shatiby menguraikan bahwa Maqasid al-Shari'ah, ditinjau dari dua bagian. Pertama, berdasar pada tujuan Tuhan selaku pembuat syariat. Kedua, berdasar pada tujuan manusia yang dibebani syariat. Pada tujuan awal, yang pertama, berkenaan dengan segi tujuan Tuhan dalam menetapkan prinsip ajaran syariat, dan dari segi ini Tuhan bertujuan menetapkannya untuk

3Yusuf al-Qardhawi, Dirasah fi Figh Maqasid al-Syari'ah Bayna al-Maqasid al-Kulliyah wa alNushush al-Juz iyah, (Beirut: Dâr al-Syurûq, 2006), h. 12.

${ }^{4}$ Ali Mutakin, Teori Maqsid Syariah dan Hubungannya dengan Metode Istibath Hukum, Kanun Jurnal Ilmu Hukum-Vol.19,.No3, (Agustus-2017) h. 542.

5Nispan Rahmi, "Maqasid al-Syariah: Melacak Gagasan Awal”, Jurnal Syariah: Jurnal Ilmu Hukum dan Pemikiran, Vol.17, Nomor 2 Desember 2017, h.160. 
dipahami, juga agar manusia yang dibebani syariat dapat melaksanakan, juga agar mereka memahami esensi hikmah syariat tersebut. Untuk dapat memahami Maqasid Shari'ah atau tujuan syari'ah itu secara sempurna, maka terlebih dahulu paparkan beberapa unsur dari Maqasid Shari'ah, yaitu Hakim, Hukum, Mahkum Fih dan Mahkum Alaih. ${ }^{6}$

Dalam syariat Islam, maka tujuan syariat Islam lebih tinggi dan bersifat abadi. Artinya tidak terbatas kepada lapangan materil saja yang bersifat sementara, karena faktor-faktor individu, masyarakat dan kemanusiaan pada umumnya selalu diperhatikan dan dirangkaikan satu sama lain, dan dengan hukum Islam dimaksudkan agar kebaikan umat manusia dapat terwujud.

\section{C.2. Klasifikasi Maqasid Syariah}

Pemebebanan hukum syari'at melekat dengan maksud-maksudnya pada makhluk. Maksud-maksud syari'at tersebut dapat diklasifikasikan kepada tiga macam, yaitu: daruriyyat, hajjiyyat, dan tahsiniyyat.

\section{Daruriyyat}

Adapun daruriyyat artinya sesuatu yang semestinya harus ada untuk menegakkan kemaslahatan, baik agama dan dunia. Seandainya hal itu tidak ada, maka rusaklah kemaslahatan dunia tidak bejalan dengan baik kegiatan dunia tersebut, dan dari aspek agama, tidak terlepas siksa Allah di akhirat dan berada dalam kerugian besar. ${ }^{7}$

Daruriyyat ini mencakup masalah dasar-dasar ibadah, adat kebiasaan dan mu'amalat. Maka masalah pokok ibadah dari aspek perbuatan yang harus dilaksananakan untuk memelihara agama, seperti beriman, mengucap dua kalimat syahadah, mendirikan shalat, membayar zakat, berpuasa di bulan Ramadhan, berhaji dan lain sebagainya, yang termasuk dalam hal-hal yang wajib dikerjakan.

Masalah adat kebiasaan meliputi hal-hal yang dapat memelihara jiwa dan akal, yaitu makan, minum, sandang dan papan, dan lain sebagainya. Dari sudut pandang daruriyyat dalam hal mu'amalat adalah memelihara keturunan dan harta, termasuk juga memelihara jiwa dan akal. ${ }^{8}$ Dengan demikian maka daruriyyat seluruhnya ada lima macam, yaitu:

a. Memelihara agama;

b. Memelihara jiwa;

c. Memelihara keturunan;

d. Memelihara harta, dan;

e. Memelihara akal.

Kelima hal tersebut ini berlaku secara universal dan dalam agama apapun di dunia ini dan termasuk dalam darurah 'ainiyyah. Karena setiap pribadi Muslim diwajibkan hal-hal tersebut di atas.

Menurut Al-Shatiby ada lima hal yang termasuk dalam kategori ini yaitu memelihara agama, jiwa, kehormatan, keturunan dan harta. Untuk

${ }^{6} \mathrm{Abu}$ Ishaq Al-Shatiby, Al-Muwafaqat fi Usul al-Shari'ah, h. 324.

${ }^{7}$ Andriyaldi, "Ijtihad Maqasidy (Kontekstualisasi Teori Maqasid Syariah di Era Modern" Jurnal al-Hurriyah, Vol.14, Nomor 01 Januari-Juni 2013, h. 24.

${ }^{8}$ Alvan Fathony, "Maqasid al-Syariah Sebagai Konsep Dasar dalam Terori Pembentukan Hukum Islam di Indonesia", Jurnal Islam Nusantara, Vol. 02, Nomor 02 (Juli-Desember 2018), h. 269. 
memelihara lima hal pokok inilah syariat Islam diturunkan. Dalam setiap ayat hukum apabila diteliti akan ditemukan alasan pembentukannya yang tidak lain adalah untuk memelihara lima hal pokok di atas. Seperti kewajiban qisas pada QS. al-Baqarah ayat 179 yang artinya:

"Dan dalam qisas itu ada (jaminan kelangsungan) hidup bagimu hai orang-orang yang bertakwa" 9

Dari QS. al-Baqarah ayat 179 ini dapat diketahui bahwa disyariatkannya qisas karena dengan itu ancaman terhadap kehidupan manusia dapat dihilangkan.

Al-Shatiby, membagi darurah, kepada dua bagian, yaitu:

a. Darurah yang ada porsi mukallaf di dalamnya, yang bersifat segera dan urgen. Seperti, mewujudkan kemasalahatan diri dan keluarganya dari makan, minum, pakaian dan papan serta hal-hal lainnya yang dianalogikan kepadanya, seperti jual beli, akad nikah dan lain-lain. ${ }^{10}$

b. Darurah yang tidak ada porsi mukallaf di dalamnya, yang bersifat segera dan urgen, baik fardhu 'ain atau kifayah. Seperti, ibadah badaniyyah atau ibadahmaliyah. Contohnya fardhu 'ain, adalah taharah, shalat, zakat, puasa, haji dan lain sewbagainya. Dalam hal fardu kifayah, seperti, pemerintahan, peradilan, jihad dan lain sebagainya yang bersifat kepentingan umum. ${ }^{11}$

\section{Hajjiyyat}

Adapun hajjiyyat, artinya sesuatu yang sangat diperlukan untuk menghilangakan kesulitan yang dapat membawa kepada hilangnya sesuatu yang dibutuhkan, tetapi tidak sampai merusak kemaslahatan umum.

Hajjiyyat ini berlaku baik pada berbagai macam ibadah, adat kebiasan, mu'amalat dan pada kriminal atau jinayat. Pada ibadah, umpamanya, pada dispensasi ringan karena sakit atau bermusafir, boleh meninggalkan puasa dan menjamakkan shalat dan memendekkannya. Pada masalah adat kebiasaan, umpanya pembolehan berburu, dan memakan makanan yang halal dan bergizi, dan lain sebagainya. Sedangkan pada mu'amalah dan jinayah adalah seperti melaksanakan transaksi qirad, jual beli salam dan lain-lain. Pada jinayah, seperti hukum sumpah atas pembunuhan berdarah (qasamah) dan kewajiban membayar diyat pembunuhan kepada keluarga pembunuh. ${ }^{12}$

\section{Tahsiniyyat}

Adapun makna tahsiniyyat adalah mengambil sesuatu yang terlebih baik dari yang baik menurut adat kebiasaan dan menjauhi hal-hal yang jelek yang tidak dirima oleh akal yang sehat, atau dalam arti lain, tahsiniyyat adalah apa yang terhimpun dalam batasan akhlak yang

${ }^{9}$ QS. al-Baqarah ayat 179.

${ }^{10} \mathrm{Abu}$ Ishaq Al-Shatiby, Al-Muwafaqat fi Usul al-Shari'ah..., h. 480.

11Ibid., h. 480.

12Ibid., h. 327. 
mulia.13 Baik dalam masalah ibadah, seperti menghilangkan najis, melakukan berbagai macam cara dalam bersuci, maupun dalam adat kebiasaan, seperti adab makan dan minum. Begitu juga dalam hal mu'amalat, seperti dilarang jual beli najis dan dicegah membunuh orang merdeka dengan sebab dia membunuh budak pada masalah jinayat atau kriminal. ${ }^{14}$

\section{C.3. Kehujjahan Maqasid Al-Shari'ah (mashlahah}

Maslahah dalam bingkai pengertian yang membatasinya bukanlah dalil yang berdiri sendiri atas dalil-dalil syara' sebagaimana al-Qur'an, al-Hadits, Ijma' dan Qiyas. Dengan demikian tidaklah mungkin menentukan hukum parsial (juz'i atau far'i) dengan berdasar kemashlahatan saja. Sesungguhnya mashlahah adalah makna yang universal yang mencakup keseluruhan bagianbagian hukum far'i yang diambil dari dalil-dalil atau dasar syariah.

Kesendirian maslahah sebagai dalil hukum, tidak dapat dilakukan karena akal tidak mungkin menangkap makna maslahah dalam masalah-masalah juz'i. Hal ini disebabkan dua hal:15

1. Kalau akal mampu menangkap Maqasid al-Shari'ah secara parsial dalam tiap-tiap ketentuan hukum, maka akal adalah penentu atau hakim sebelum datangnya syara'. Hal ini mungkin menurut mayoritas ulama.

2. Kalau anggapan bahwa akal mampu menangkap Maqasid Al-Shari'ah secara parsial dalam tiap-tiap ketentuan hukum itu dianggap sah-sah saja maka batallah keberadaan atsar atau efek dari kebanyakan dalil-dalil rinci bagi hukum, karena kesamaran substansi maslahah bagi mayoritas akal manusia. Bagi 'Abd al-Wahhab Khallaf, Maqasid Al-Shari'ah adalah suatu alat bantu untuk memahami redaksi Al-Qur'an dan Al-Hadits, menyelesaikan dalil-dalil yang bertentangan dan menetapkan hukum terhadap kasus yang tidak tertampung dalam Al Qur'an dan Al Hadits.16 Dari apa yang disampaikan 'Abd al-Wahhab Khallaf ini, menunjukkan Maqasid Al-Shari'ah tidaklah mandiri sebagai dalil hukum tetapi merupakan dasar bagi penetapan hukum melalui beberapa metode pengambilan hukum.

\section{C.4. Maqasid Shari'ah Sebagai Metode dalam Penemuan Hukum}

Hal yang menarik ketika membahas tentang Maqasid Syar'iah sebagai metode dalam penemuan hukum adalah melalui Maqasid Syar'iah dapat dijadikan pendekatan dalam berijtihad dalam rangka merespon perkembangan zaman dengan tetap mengacu pada al-Qur'an dan al-Hadis, maka dengan menggunakan Maqasid Syar'iah akan Menuju fiqh baru yakni Madrasah Moderat; dengan menggabungkan teks-teks partikular dan maksud-maksud global. Fiqh baru ini dibangun oleh madrasah moderat yang tidak melupakan teks-teks partikular dari Al-Quran dan Sunnah, tetapi dalam satu waktu juga tidak

${ }^{13} \mathrm{Abu}$ Ishaq Al-Shatiby, Al-Muwafaqat fi Usul al-Shari'ah..., h. 327.

${ }^{14}$ Retna Gumati, “Maqasid al-Syariah Menurut Jasser Auda Pendekatan Sistem dalam Hukum Islam", Jurnal Al-Himayah, Vol. 2, Nomor 01 (Maret 2018), h. 97.

${ }^{15}$ Nispan Rahmi, “Maqasid al-Syariah: Melacak Gagasan Awal”, Jurnal Syariah: Jurnal Ilmu Hukum dan Pemikiran, Vol.17, Nomor 2 Desember 2017, h.163.

16Maman Suherman, "Aliran Ushul Fiqh dan Maqasid Syari'ah", Jurnal Al-Maslahah: Jurnal Hukum Islam dan Pranata Sosial Islam, Vol. 2, Nomor 04, h. 353. 
memisahkannya dari maksud-maksud global. Bahkan teks-teks partikular tersebut dipahami dalam bingkai maksud-maksud global.

Mengembalikan furu' kepada usul, particular kepada global, mutashbihat kepada muhkamat, juga memegang teguh ijma' ulama dan menjadikan jalan orang-orang mukmin tidak boleh dilanggar. Manhaj inilah yang ditempuh para ulama penggagas dan penerus teori Maqasid Shari'ah, seperti al-Juwaini, al-Gazali, Rashid Rida, Al-Shatiby, Ibn 'Ashur, Qaradawi dan lain sebagainya. Madrasah ini yang dipercaya, dijadikan sebagai gambaran yang benar tentang hakekat Islam, membantah kebatilan orang-orang yang memusuhinya, serta berbaik sangka kepada Allah dan RasulNya dalam semua hukumNya. ${ }^{17}$ Fiqh yang dihasilkan oleh mereka, bisa menjelaskan tujuan, menerangi jalan, menyinari pandangan menuju manhaj Islam yang lurus. Dan kita tidak ditimpa oleh kegelapan dalam memahami agama daan dunia. 18

Sedangkan untuk menetapkan Maqasid Syariah dalam penemuan hukum dapat dilakukan dengan tiga cara, yakni:

1. Dengan cara istigra' (pengambilan beberapa sampel) bagi syari'at yang diterapkan. Cara ini adalah yang terbaik dalam mendapatkan Maqasid Shari'ah, dan terbagi ke dalam dua macam dan yang paling baik dari dua macam itu adalah memeriksa sampel hukum-hukum yang telah diketahui illat-nya, kemudian memeriksa illat tersebut pada proses pengambilan hukum. Maka, dengan demikian dimungkinkan akan dipaham maksud syari' at melalui istiqra' ${ }^{19}$

2. Metode mengkaji dalil ayat-ayat al-Quran yang jelas dilalahnya, sehingga dengan demikian kecil kemungkinan maksud suatu ayat bukan seperti lahir penggunaan kaedah bahasa Arab atau diragukan maksud lahir maknanya. ${ }^{20}$

3. Metode melihat hadis mutawatir, baikmutawatir ma'nawi atau mutawatir' 'amali. Mutawatir maknawi adalah mutawatir yang diperoleh dari pengamatan prilaku para sahabat mengamalkan semuanya apa dilihat dari pada Nabi saw. Dengan demikian dapat menghasilakan ilmu yang meyakinkan pada masalah agama. Sedangkanmutawatir 'amali adalah apa yang diperoleh oleh seorang sahabat dari perbuatan Nabi yang berulang-ulang, sehingga dia berkesimpulan bahwa begitulah maksud syari'at di situ. ${ }^{21}$

Sedangkan Ibn 'Ashur menyimpulkan bahwa, maksud Syari' dapat diketahui dengan beberapa jalan:

1. Semata-mata perintah atau larangan yang jelas sejak awalnya;

2. Memperhatikan illat perintah atau larangan, dan;

3. Bagi Syari' dalam menetapkan hukum pasti ada maksud-maksud baik asli atau cabang, maka ada yang sudah dijelaskan, ada yang dengan isyarat

17Yusuf al-Qardhawi, Dirasah fi Figh Maqasid al-Syari'ah Bayna al-Maqasid al-Kulliyah wa alNushush al-Juz iyah, h. 12.

18Ibid., h. 9.

${ }^{19}$ Muhammad Tahir ibn 'Ashur, Maqasid Shari'ah Islamiyah, (Tunisia: Dar as-Salam, 2006), h. 17.

20Ibid., h. 19.

21Ibid., 
dan ada pula lewat penelitian sampel pada nash-nash hukum. Dari situlah akan dipahami maksud Syari'.22

Tingkat kebutuhan ini berupa kebutuhan pelengkap, seperti dikemukakan al-Shatiby seperti hal yang merupakan kepatutan menurut adat-istiadat menghindari hal yang tidak enak dipandang mata dan berhias dengan keindahan yang sesuai dengan tuntutan norma dan akhlak, dalam berbagai bidang kehidupan seperti ibadah muamalah, dan'uqubah. Allah swt telah mensyariatkan hal yang berhubungan dengan kebutuhan tahsinat. Contoh anjuran berhias ketika hendak ke masjid, anjuran memperbanyak ibadah sunnah, larangan penyiksaan mayat dalam peperangan.

Al-Shatiby membagi maslahah dalam tiga hal:23

1. Maslahah mu'tabar, yaitu kemashlahatan yang berhubungan dengan penjagaan pada lima hal sebagaimana diungkap di atas. Usaha pemeliharaan kemashlahatan yang lima ini adalah pemeliharaaan yang doruri (yang paling utama). Itulah sebabnya diharuskannya berjihad kepada yang kuat fisiknya untuk melawan serangan musuh yang bermaksud menghancurkan agama dan tanah air. Ditetapkannya hukuman qisas untuk menjamin keselamatan jiwa, dan lain-lain.

2. Maslahah mulgha, yaitu sesuatu yang sepintas lalu terlihat maslahah, tetapi ada maslahah yang lebih besar sehingga maslahah yang kecil itu boleh diabaikan. Sebagai contoh, pada suatu ketika 'Abd ar-Rahman ibn Hakam, gubernur Andalusia, meminta fatwa kepada Imam al-Laithi tentang kafarat karena telah membatalkan puasa Ramadhan dengan mencampuri istrinya di siang hari. Al-Laithi memfatwakan bahwa kafaratnya harus berpuasa dua bulan berturut-turut. Pengambilan keputusan ini diambil dengan argumen bahwa memerdekakan budak atau memberi makan 60 oarang miskin terlalu ringan bagi seorang gubernur, maka dikawatirkan sang gubernur meremehkannya. Kemashlahatan yang lebih besar dalam kasus ini adalah kemashlahatan agama.

3. Maslaha mursalah, yaitu kemashlahatan yang tidak terkait dengan dalil yang memperbolehkan atau melarangnya, contoh untuk mengatasi merajalelanya pemalsuan hak milik atas barang-barang berharga atau pemalsuan isteri agar dapat bebas kumpul kebo maka atas pertimbangan maslahah mursalah boleh diadakan ketentuan kewajiban mencatat dan keharusan mempunyai keterangan yang sah setiap terjadi akad jual beli, nikah, hibah dan lain sebagainya.

Sedangkan Ketentuan Maqasid Syar'iah, Wahbah az-Zuhail berpendapat tidak setiap yang diduga sebagai maqasid itu dapat diterima untuk memutuskan hukum, meskipun disinyalir ada nilai kemaslahatan di dalamnya karena letaknya yang tersembunyi menjadikan ia bersifat relatif-subyektif yang rentan hanya didasarkan pada rasio akal manusia, sehingga perlu adanya syarat dalam penetapan maqasid al-shari'ah. 24 Syarat-syarat tersebut di antaranya adalah harus nyata, jelas, terukur, dan dapat berlaku selamanya:25

22Ahmad al-Mursi Husain Jauhar, Maqashid Syariah fi al-Islam, Terj.Hikmawati, (Jakarta: Amzah, 2012), h. 26.

${ }^{23} \mathrm{Abu}$ Ishaq Al-Shatiby, Al-Muwafaqat fi Usul al-Shari'ah..., h. 480.

${ }^{24}$ Mayoritas dari syarat-syarat tersebut adalah sesuai dengan syarat'illah, sebab para ulama' menyebutkan bahwa 'illah sebenarnya adalah bagian dari maqasid al-shari'ah. Muhammad Sa'id 
1. Nyata (Thubut), yakni maqasid tersebut adalah sifat yang benar-benar ada atau diduga kuat ada.

2. Jelas (dzuhur), yakni sudah jelas tanpa diperdebatkan pemahamannya seperti tujuan hifz al-nasb terhadap disyariatkanya nikah. Tujuan ini jelas dan tidak ada konsep lain selain nikah. Sifat yang tidak jelas seperti perasaan "ridlo" karena perbuatan hati sehigga tidak bisa ditetapkan sebagai maqasid dalam jual-beli, kemudian shara' menetapkan adanya ijabkabul sebagai petunjuk "ridlo" tersebut.

3. Terukur (indlibat), yakni memiliki batasan yang jelas, tepat dan akurat.

4. Dapat berlaku selamanya (ittirad) sehingga tidak berubah dalam situasi dan kondisi yang berbeda.

Ketika suatu sifat telah sesuai dengan keempat ketentuan di atas, maka itu adalah Maqasid Syar'iah.

\section{Simpulan}

Disini penulis bisa menyimpulkan Bahwa Maqasid Shari'ah merupakan konsep untuk mengetahui Hikmah (nilai-nilai dan sasaran syara' yang tersurat dan tersirat dalam al-Qur'an dan Hadits). yang ditetapkan oleh al-Syari' terhadap manusia adapun tujuan akhir hukum tersebut adalah satu, yaitu maslahah atau kebaikan dan kesejahteraan umat manusia baik didunia (dengan Mu'amalah) maupun di akhirat (dengan 'aqidah dan Ibadah). sedangkan cara untuk tercapainya kemaslahatan tersebut manusia harus memenuhi kebutuhan $D$ \{aruriyyat (Primer), dan menyempurnakan kebutuhan Hajiyyat (sekunder), dan Tahsiniyyat atau Kamaliyyat (tersier) berdasarkan skala prioritas. Secara substansial maqasid al-shari' mengandung kemashlahatan, kalau dilihat dari sudut Maqasid Shari' (tujuan Tuhan) kemeslahatan itu bisa terbagi kepada empat aspek pertama tujuan tuhan adalah Penetapan syariah untuk kemashlahatan manusia di dunia dan akhirat. untuk tercapainya kemashlahatan tersebut tidak ada pilihan lain kecuali melalui pemeliharaan lima unsur pokok, yaitu agama, jiwa, Aqal, keturunan dan harta. Mengabaikan hal ini sama juga dengan merusak visi dan misi hkum islam. Dengan demikian akan menuai kemudharatan atau kesengsaraan hidup. Aspek kedua tujuan Allah adalah Penetapan syariah sebagai sesuatu yang harus dipahami. Aspek ini berkaitan dengan dimensi bahasa agar syariat dapat dipahami sehingga dicapai kemashlahatan yang dikandungnya. Aspek ketiga adalah Penetapan syariah sebagai hukum taklifi yang harus dilaksanakan. Aspek ini berkaitan dengan kemampuan manusia untuk melaksanakannya. Sedangkan aspek yang terakhir adalah Penetapan Syari'ah guna membawa manusia terhindar dari mengikuti Hawa nafsu. Aspek ini berkaitan dengan kepatuhan manusia sebagai mukallaf terhadap hukum-hukum Allah Swt. Sedangkan untuk memahami Maqasid al-Shari'ah perlu adanyanya metode ijtihad (Ijtihad istinbati dan Ijtihad Muntabiqi) oleh karena itu Maqasid al-Shari'ah ada keterkaitan antara Ijtihad, keterkaitan antara Maqasid al-Shari'ah dengan Ijtihad adalah keterkaitan antara teori perumusan hukum dengan metodelogi perumusan hukum-hukum Islam. Maqasid al-Syari'ah membicarakan persoalan

Ramadan al-Buti, Dawabit al-Maslahah fi al-Shari'ah al-Islamiyyah. (Damaskus: Muassasah al-Risalah, 1973), hal 218

${ }^{25}$ Auda, Jasser, Maqasid al-Shari'ah as Philosophy of Islamic Law. (London: Washington: IIT, 2008), h. 47. 
hukum pada level tioritis, sedangkan Ijtihad menyajikan prosedur dan teknisteknis Istimbat hukum. Selain itu menurut Wahbah az-Zuhaily ketentuan untuk menilai apakah probelmatika yang muncul dimsayarakat itu bisa diselesaikan dengan maqasid as-Syari'ah atau tidak harus memenuhi syarat yaitu: nyata (Thubut). jelas (dzuhur), terukur (indibath), dan dapat berlaku selamanya (ittirad).

\section{Referansi:}

Abu Ishaq Al-Shatiby, Al-Muwafaqat fi Usul al-Shari'ah, Libanon: Dar alMa'rifah,1997.

Ahmad al-Mursi Husain Jauhar, Maqashid Syariah fi al-Islam, Terj.Hikmawati, Jakarta: Amzah, 2012.

Ali Mutakin, Teori Maqsid Syariah dan Hubungannya dengan Metode Istibath Hukum, Kanun Jurnal Ilmu Hukum-Vol.19,.No3, (Agustus-2017)

Alvan Fathony, "Maqasid al-Syariah Sebagai Konsep Dasar dalam Terori Pembentukan Hukum Islam di Indonesia", Jurnal Islam Nusantara, Vol. 02, Nomor 02 (Juli-Desember 2018).

Andriyaldi, "Ijtihad Maqasidy (Kontekstualisasi Teori Maqasid Syariah di Era Modern" Jurnal al-Hurriyah, Vol.14, Nomor 01 Januari-Juni 2013.

Auda, Jasser, Maqasid al-Shari'ah as Philosophy of Islamic Law. London: Washington: IIT, 2008.

Firdaus, Ushul Figh, Jakarta: Zikrul Hakim, 2004.

Maman Suherman, "Aliran Ushul Fiqh dan Maqasid Syari'ah", Jurnal AlMaslahah: Jurnal Hukum Islam dan Pranata Sosial Islam, Vol. 2, Nomor 04.

Muhammad Sa'id Ramadan al-Buti, Dawabit al-Maslahah fi al-Shari'ah alIslamiyyah. Damaskus: Muassasah al-Risalah, 1973.

Muhammad Tahir ibn 'Ashur, Maqasid Shari'ah Islamiyah, Tunisia: Dar as-Salam, 2006.

Nispan Rahmi, "Maqasid al-Syariah: Melacak Gagasan Awal", Jurnal Syariah: Jurnal Ilmu Hukum dan Pemikiran, Vol.17, Nomor 2 Desember 2017.

Retna Gumati, "Maqasid al-Syariah Menurut Jasser Auda Pendekatan Sistem dalam Hukum Islam", Jurnal Al-Himayah, Vol. 2, Nomor 01 (Maret 2018).

Wahbah az-Zuhaily, al-Wajiz fi Usul al-Figh, Beirut: Dar al-Fikr, 2010

Yusuf al-Qardhawi, Dirasah fi Figh Maqasid al-Syari'ah Bayna al-Maqasid al-Kulliyah wa al-Nushush al-Juz iyah, Beirut: Dâr al-Syurûq, 2006. 